\title{
Increased dosing regimens of piperacillin-tazobactam are needed to avoid subtherapeutic exposure in critically ill patients with augmented renal clearance
}

\author{
Thibaud Besnard ${ }^{1}$, Cédric Carrié ${ }^{1,3^{*}}$, Laurent Petit ${ }^{1}$ and Matthieu Biais ${ }^{1,2}$
}

Keywords: Augmented renal clearance, Piperacillin, Critical care

\section{Dear Editor,}

In intensive care settings, augmented renal clearance (ARC) is recognized as a leading cause of subtherapeutic antibiotic exposure, and piperacillintazobactam (PTZ) has been the most frequently studied antibiotic in this context [1-5] (Table 1). We, like others, previously suggested that higher than licensed dosing regimens should be necessary for empirical treatment in patients with ARC $[4,5]$. We thus aimed to determine the efficacy and tolerability of such a strategy.

For this purpose, we performed a retrospective analysis of our local database over a 10-month period (February to November 2018). Ethical approval confirmed the observational design of the study (IRB number: CERAR 00010254-2018-074). Over the study period, every patient with a 24-h measured creatinine clearance $\left(\mathrm{CL}_{\mathrm{Cr}}\right) \geq 150 \mathrm{~mL} / \mathrm{min}$ received increased dosing regimens of PTZ $(20 / 2.5 \mathrm{~g}$ daily after a loading dose of $4 / 0.5 \mathrm{~g}$ over $60 \mathrm{~min}$ ) [4]. Subsequent dose adjustments were guided by therapeutic drug monitoring performed between 24 and $72 \mathrm{~h}$ of antimicrobial therapy. As previously described, observed concentrations were corrected for protein binding ( $30 \%$ for piperacillin) to estimate unbound fraction [1].

As MIC data are often not available to the clinician prescribing an empirical antimicrobial regimen, piperacillin underdosing was defined by an unbound concentration under $16 \mathrm{mg} / \mathrm{L}$, representing the highest MIC for Pseudomonas as per the European Committee on Antimicrobial Susceptibility Testing (EUCAST) [4]. Empirical underdosing for tazobactam was defined by an unbound concentration under $2 \mathrm{mg} / \mathrm{L}$, representing the highest MIC for high-level $\beta$-lactamase-producing strains [4]. Excessive dosing was defined as a free drug concentration above 150 $\mathrm{mg} / \mathrm{L}[4]$.

\footnotetext{
* Correspondence: cedric.carrie@chu-bordeaux.fr

${ }^{1}$ Anesthesiology and Critical Care Department, CHU Bordeaux, 33000 Bordeaux, France

${ }^{3}$ Surgical and Trauma Intensive Care Unit, Anesthesiology and Critical Care Department, Hôpital Pellegrin, CHU Bordeaux, Place Amélie Raba Léon, 33076 Bordeaux Cedex, France

Full list of author information is available at the end of the article
} 


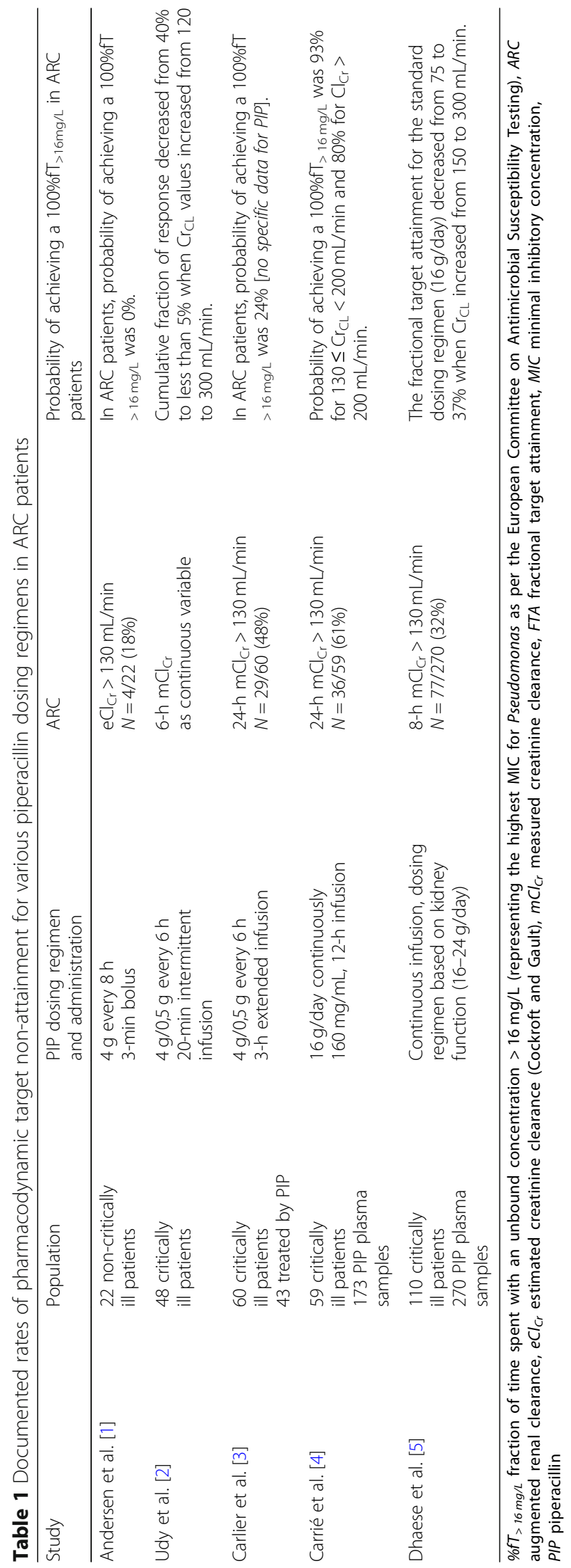


Table 2 Characteristics of the population

\begin{tabular}{|c|c|}
\hline Variable & $\begin{array}{l}\text { Overall population } \\
N=35\end{array}$ \\
\hline \multicolumn{2}{|l|}{ Demographic data } \\
\hline - Age (years) & 48 [37-57] \\
\hline - Male sex & $31(89)$ \\
\hline - BMI $\left(\mathrm{kg} / \mathrm{m}^{2}\right)$ & 25 [22-29] \\
\hline \multicolumn{2}{|l|}{ Admission } \\
\hline - Polytrauma & $30(86)$ \\
\hline - Non-traumatic surgery & $5(14)$ \\
\hline SAPS ॥ & $42[34-51]$ \\
\hline \multicolumn{2}{|l|}{ Presumed/confirmed site of infection } \\
\hline - Pulmonary infection & $31(89)$ \\
\hline - Intra-abdominal infection & $3(9)$ \\
\hline - Intravascular-catheter-related infection & $1(3)$ \\
\hline Bacteremia & $2(6)$ \\
\hline Use of vasopressors & $12(34)$ \\
\hline Modified SOFA score* & $3[1-6]$ \\
\hline $\mathrm{CL}_{\mathrm{Cr}_{r}}$ the day of therapeutic drug monitoring & 166 [159-191] \\
\hline \multicolumn{2}{|l|}{ Antimicrobial therapy } \\
\hline - Duration of antibiotic therapy before TDM & $2[1-3]$ \\
\hline - Association with aminoglycoside or quinolone & $8(23)$ \\
\hline - De-escalation & $9(26)$ \\
\hline - Total duration of antimicrobial therapy (days) & $7[5-7]$ \\
\hline \multicolumn{2}{|l|}{ Type of pathogen } \\
\hline - Enterobacteriaceae & $33(94)$ \\
\hline - Staphylococcus spp. & $18(51)$ \\
\hline - Haemophilus influenzae & $8(23)$ \\
\hline - Non-fermenting GNB & $3(9)$ \\
\hline - Other & $3(9)$ \\
\hline Polymicrobial infection & $20(57)$ \\
\hline Non-documented infection & $1(3)$ \\
\hline \multicolumn{2}{|l|}{ PK/PD targets } \\
\hline - Piperacillin unbound concentrations (mg/L) & $36.4[27.7-44.3]$ \\
\hline Empirical underdosing for piperacillin & $0(0)$ \\
\hline Excessive dosing for piperacillin & $0(0)$ \\
\hline - Tazobactam unbound concentrations (mg/L) & $4.55[3.57-5.88]$ \\
\hline Empirical underdosing for tazobactam & $1(3)$ \\
\hline - PIP/TAZ ratio & $9.1[6.9-11.1]$ \\
\hline \multicolumn{2}{|l|}{ Clinical outcomes } \\
\hline - Therapeutic failure before end of treatment & $2(6)$ \\
\hline - Relapse after end of treatment & $1(3)$ \\
\hline
\end{tabular}

Table 2 Characteristics of the population (Continued)

\begin{tabular}{ll}
\hline Variable & $\begin{array}{l}\text { Overall population } \\
N=35\end{array}$ \\
\hline Secondary resistance to PTZ & $3(9)$ \\
MV duration (days) & $14[4-26]$ \\
ICU length of stay (days) & $22[14-37]$ \\
ICU mortality & $0(0)$
\end{tabular}

Results expressed as median [25-75 interquartile] and numbers (percentage). Therapeutic failure was defined as an impaired response (persistent or recurrent fever, organ dysfunction, clinical and biological symptoms of the initial infection) with the need for escalating empirical antimicrobial therapy. Relapse was defined by a recurrent infection within 15 days after completing antibiotic therapy with at least one of the initial causative bacterial strains growing at a significant concentration from a second sample

*Sepsis-related Organ Failure Assessment score, without neurologic and renal components

The final dataset consisted of 36 PTZ samples collected from 35 patients. The main characteristics and outcomes of these patients are resumed in Table 2. Except for one tazobactam sample, all samples were in the therapeutic range (Fig. 1). No patient experienced excessive dosing above the supposed toxic cutoff $\geq 150 \mathrm{mg} / \mathrm{L}$. Three of them (9\%) experienced therapeutic failure or relapse [4], all related to secondary acquisition of antimicrobial resistance.

When targeting a theoretical MIC at the upper limit of the susceptibility range, higher than licensed doses of PTZ allowed achieving the pharmacodynamic target in all patients with $\mathrm{CL}_{\mathrm{Cr}} \geq 150 \mathrm{~mL} / \mathrm{min}$, without excessive dosing. Further studies are warranted to confirm if such a strategy improves the rate of therapeutic success.
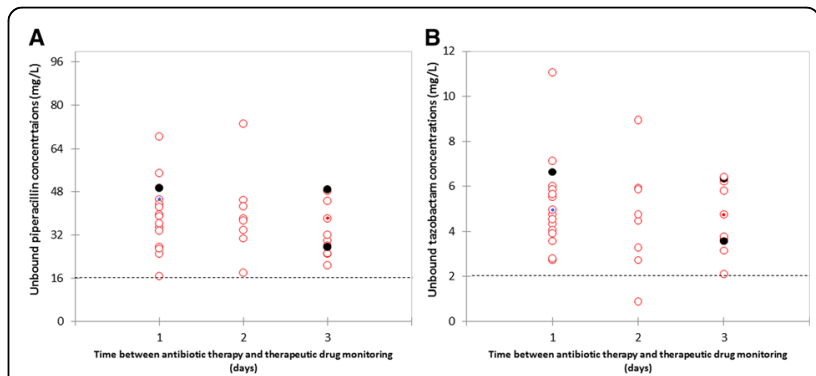

Fig. 1 Unbound steady-state concentrations (mg/L) of piperacillin (a) and tazobactam (b) using higher than licensed dosing regimens $(20 \mathrm{~g} /$ day $[160 \mathrm{mg} / \mathrm{mL}, 10-\mathrm{h}$ infusion] after a loading dose of $4 \mathrm{~g}$ ) in critically ill patients with ARC $\left(\mathrm{Cl}_{\mathrm{Cr}} \geq 150 \mathrm{~mL} / \mathrm{min}\right.$ the first day of antimicrobial therapy). The dotted line indicates underdosing threshold for piperacillin (fixed at $16 \mathrm{mg} / \mathrm{L}$ ) and tazobactam (fixed at $2 \mathrm{mg} / \mathrm{L}$ ) [4]. The black circles indicate samples from patients who experienced therapeutic failure [4] 


\section{Abbreviations}

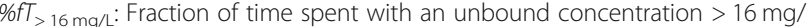
$L$ (representing the highest MIC for Pseudomonas as per the European Committee on Antimicrobial Susceptibility Testing); ARC: Augmented renal clearance; $\mathrm{Cl}_{\mathrm{Cr}}$ : Creatinine clearance; $\mathrm{eCl}_{\mathrm{Cr}}$ : Estimated creatinine clearance (Cockcroft and Gault); FTA: Fractional target attainment; $\mathrm{mCl}_{\mathrm{Cr}}$ : Measured creatinine clearance; MIC: Minimum inhibitory concentration; PIP: Piperacillin; PTZ: Piperacillin-Tazobactam

\section{Acknowledgements}

The authors thank members of the Department of Laboratory Medicine at Paris Saint Joseph University Hospital for their contribution for samples storage, preparation and quantification.

\section{Funding}

Only departmental funds were used for this study. No external funds were obtained.

\section{Availability of data and materials}

The datasets used and/or analyzed during the current study are available from the corresponding author on reasonable request.

\section{Authors' contributions}

CC and LP designed the study. TB recruited the patients and collected the data. CC and TB wrote the manuscript. CC, LP, and MB have personally reviewed the data and confirmed that the methods are clearly described and that they are a fair way to report the results. All authors read and approved the final manuscript.

\section{Ethics approval and consent to participate}

Ethical approval was obtained from the Ethics Committee of the French Society of Anesthesiology and Intensive Care (IRB number: CERAR 000102542018-074). Our local database was declared to the French Data Protection Authority (declaration number $2166637 v 0)$. The patients and/or next of kin were informed about the inclusion of their anonymized health data in the database, and none declined participation.

\section{Consent for publication}

Not applicable

\section{Competing interests}

The authors declare that they have no competing interests.

\section{Publisher's Note}

Springer Nature remains neutral with regard to jurisdictional claims in published maps and institutional affiliations.

\section{Author details}

${ }^{1}$ Anesthesiology and Critical Care Department, CHU Bordeaux, 33000 Bordeaux, France. ${ }^{2}$ Université Bordeaux Segalen, 33000 Bordeaux, France. ${ }^{3}$ Surgical and Trauma Intensive Care Unit, Anesthesiology and Critical Care Department, Hôpital Pellegrin, CHU Bordeaux, Place Amélie Raba Léon, 33076 Bordeaux Cedex, France.

Received: 5 December 2018 Accepted: 3 January 2019

Published online: 16 January 2019

\section{References}

1. Andersen MG, Thorsted A, Storgaard M, Kristoffersson AN, Friberg LE, Öbrink-Hansen K. Population pharmacokinetics of piperacillin in sepsis patients: should alternative dosing strategies be considered? Antimicrob Agents Chemother. 2018;62(5).

2. Udy AA, Lipman J, Jarrett P, Klein K, Wallis SC, Patel K, Kirkpatrick CM, Kruger PS, Paterson DL, Roberts MS, Roberts JA. Are standard doses of piperacillin sufficient for critically ill patients with augmented creatinine clearance? Crit Care. 2015;19:28

3. Carlier M, Carrette S, Roberts JA, Stove V, Verstraete A, Hoste E, Depuydt P, Decruyenaere J, Lipman J, Wallis SC, De Waele JJ. Meropenem and piperacillin/tazobactam prescribing in critically ill patients: does augmented renal clearance affect pharmacokinetic/pharmacodynamic target attainment when extended infusions are used? Crit Care. 2013;17(3):R84.
4. Carrié C, Legeron R, Petit L, Ollivier J, Cottenceau V, d'Houdain N, Boyer P, Lafitte M, Xuereb F, Sztark F, Breilh D, Biais M. Higher than standard dosing regimen are needed to achieve optimal antibiotic exposure in critically ill patients with augmented renal clearance receiving piperacillin-tazobactam administered by continuous infusion. J Crit Care. 2018;48:66-71.

5. Dhaese SAM, Roberts JA, Carlier M, Verstraete AG, Stove V, De Waele JJ. Population pharmacokinetics of continuous infusion of piperacillin in critically ill patients. Int J Antimicrob Agents. 2018;51(4):594-600. 